\title{
POST COMPUTER ART - ONTOLOGICAL UNDECIDABILITY AND THE CAT WITH PAINT ON ITS PAWS
}

\author{
Brian Reffin-Smith
}

What comes after 'computer art' depends on revisiting past concepts not fully explored. A true revolution involves seeing the past before returning to change the present.

\section{KEYNOTE}

First I'll say how pleased I am to be giving this keynote talk. The speakers presenting their theory, practice and ideas at this conference will, I'm sure, be reason enough to support the premise of 'rediscovering things lost' that I evoked in the text which the organisers have been kind enough to recognise.

I should note here that I'm very much in favour of a 'two for the price of one' approach to conference talks, so the text that I shall perform 'live' as it were, will differ markedly from this one, and the title of both has precious little to do with the contents of either - I just liked it.

I'm also going to allow myself a smile in passing because in a way, it's a kind of vindication. Although I was quite in demand at conferences and other events in the seventies and eighties there was a period during which the phone rang less often, and I know that this was because I tended to reject some of the more - shall we say 'optimistic' — 'blatantly hubristic' — 'hysterically triumphalist' — yet terribly mundane in art terms - products from the world of computer based arts.

I wanted, as did some others, to see a contribution to contemporary art, a pushing of the art frontiers, a recognition that if you were only interested in using state-of-the-art technology, you might end up merely producing state-of-the-technology art. Not everyone agreed with this attitude. Thus art ideas were often subsumed into or consumed by technical ideas. There just wasn't time to follow up the art, because the next new thing beckoned. More colours, more pixels, more processing power... as if the art would become twice as good by doubling the screen resolution. Furthermore the vision of 'art' involved with this process was, I shall argue, deeply spurious, oldfashioned and simplistic. Thus we already have two reasons for...failure.

In Kuhnian terms, there are no periods of 'normal' computer art, which is in constant 'revolution' or the constant appearance of revolution. It is as Marx predicted of late 


\section{CAT 2010 London Conference $\sim 3^{\text {rd }}$ February Brian Reffin-Smith}

capitalism: 'All that is solid floats into air'. And really, how we love that! How we shiver with pleasure in front of the virtual, the first generation ever to sense not only that, as Jean Baudrillard put it, the Gulf war did not take place, but that in a sense, nothing does. We think it connects us with quantality and the cosmos, but it's more likely to be a marketing strategy.

However when I wrote an article for Leonardo Journal in which I stated that much computer art was complete nonsense qua art, and that everyone knew this but daren't say so, it was amazing the response I got, with no critical letters at all, but about 15 people - from within the field - saying how much they agreed. In passing, I also satirically transposed my address from West to East Berlin, and thanked the German Democratic Republic's Naval Ordnance Laboratory for their support. My phone got tapped; by which side I don't know.

I now hasten to say that I'm delighted that the speakers today are people who invest their work with critical insight, with an artistic and/or creative impulse that means their contributions go to pushing the envelope, not posting it to Bill Gates asking for sponsorship for some all-singing, all-dancing, meretricious display that in the end goes nowhere. Some of them have been doing this for a long time (I mean the former of course!) working quietly as artists or designers or theoreticians who use computers. I have known some of them for many years, and have been honoured to study, teach or work with them. Other heroes, such as Professor Friede Nake, I am so pleased to have met personally relatively recently, better late than never, and to have exchanged and celebrated ideas with them.

But I have to ask: is working quietly now enough? In an art world - and a technological world - where it often seems that the possessor of the loudest voice, the most cynical gallerist, the most mystified critics or the most gangsterish friends is the one who triumphs - in such a world, can we really rely on the excellence of our ideas, the stoutness of our core values, the rigour of our systems, to get us to a place where our work makes a real contribution to contemporary art? And gets shown, criticised, incorporated not into the academy but into the new avant-garde? Even if we're not yBa's, but oBa's?

We might ask: would it be enough merely to reiterate and re-explore ideas that were current and then neglected in previous decades; or even to go back and unearth dormant or latent art concepts that can be used today to make a bigger splash in contemporary art? And if not, if that quiet, considered, reformist approach would be too little, too late...then what could or should we do?

Let me take just two examples, and try to analyse where they might suggest a reexamination, in their 'opening up', an augmentation of their conceptual richness. Both 


\section{CAT 2010 London Conference $\sim 3^{\text {rd }}$ February Brian Reffin-Smith}

these examples are from rather conventional 2-dimensional computer-based art, and I'm aware that the field was and is vast, and included far richer areas of activity. I'm sure we will hear a lot more about them later today.

Do you remember the early video digitisers, or frame-grabbers? I had three: one for my BBC Micro, with its stunning 32K of memory; one for my later Amiga 1000 with its over-the-top, wholly bloated 256K, and one, home made, for the Research Machines $380 \mathrm{Z}$ with its (extraordinary for the time) 56k and a floppy disc the size of a dustbin lid. (In passing, let us remember that a good art idea is a good art idea, whether it be done with a pencil and paper or a top of the range Mac. A bad one won't be saved by all the chips in China. As Oscar Wilde nearly said, there is only one thing worse than too little memory... and that is too much memory.) I knew you'd agree...

These digitisers had one thing in common: they were very...very...slow. They took up to 20 seconds to scan the image from left to right, or was it right to left, and in any case reversed... or not... anyway it took a long time. The Amiga could even do it in colour, you had to do it three times with a bit of red, green and blue plastic in front of the monochrome cctv camera.

BUT...! Because it took a long time, you could introduce things - ideas, crazy stuff into that time and space. You could think while the 'instant' was recorded. It wasn't photography but it wasn't video either. You could move with the digitising edge, extending the size of your nose, or in my own case trying to reduce it. You could jump up and down, introduce objects into the scene suddenly, you know: 'portrait with half an ash try', or you could, by spinning slowly on a chair, have a $360^{\circ}$ — or more! representation of your head or... anything. With the Amiga, you could make the red, green and blue components of the image be of different things! The naughtiness - the creativity - of that!

Today we have more or less instant digitisation but you can't get at it, so to speak. Pace Jean-Luc Godard, if film was the truth 24 times a second, European video the truth 25 times a second, and Siggraph lies once a year, then these digitisers were...something else...somewhere else...some when else, let's say.

My second example is that of the pen plotter. Now I realise that both my examples are not art or computer art ideas per se, but tools or techniques. However, I assert that it was out of these techniques that the ideas came. Doesn't this go completely against what I said before, about work needing to be art led, not technique led? Well, yes and no, in the Derridean sense of being simultaneously true and false. I am going to suggest that the very idea of uncertainty, of paradox, of the fuzzy, of the undecidable, might be central to what we might do in art. Schrödinger's cat has paint on its paws. 


\section{CAT 2010 London Conference $\sim 3^{\text {rd }}$ February Brian Reffin-Smith}

The pen plotter differed from today's ink-jet plotter in two significant respects: you weren't limited to using just one method - the spot of ink - because it could draw absolutely continuous lines, vectorially or just, you know, lines... and the image did not usually appear progressively from top to bottom or left to right, but rather in the order the program told it to draw, either algorithmically or following the user's instructions. You could stop when you felt like. Half a pen plotter drawing was a very different thing to half an ink jet print. Further you could replace the pens by pencils, crayons, felt-tips, paintbrushes, charcoal, silver point... It might have a precision of $0.01 \mathrm{~mm}$, but with a wobbly paintbrush in place, swerving round corners, you could develop a trace that was neither computer nor painterly, but 'other' than that. Now, apart from a few specialist machines constructed by artists, there are very few pen plotters left, making art. You go from image on the screen to a photograph-like representation on not very good paper, and can hardly interfere with it. A whole chunk of the process has been removed, with not even the possibility to get in there as you could with a Polaroid instant camera, which of course was not instant at all.

I suggest that in the matter of drawing, there were things done from about 1970 to about 2000 with pen plotters which might have opened new ways of doing, looking at, talking and thinking about that kind of mark-making. Except...they didn't, or didn't much, because ink jets came along, and we wanted solid images, not hidden line or wire-frame drawings.

The act of drawing should have, but didn't really, become - let's say 'become again' - problematised, 'difficult', and even though the process was electro-mechanical, it might in some respects have become even richer.

A reformist approach takes difficult problems and tries to bring them down to a level of simplicity and understanding. A revolutionary approach on the contrary might take what appear to be simple questions or accepted existing 'solutions' and render them problematic or 'difficult'. Conceptual art, I would suggest, was busy doing that, whilst computer based art was doing the opposite, reformist task of 'de-complicating' things. This might be fine, but it does go to explaining why there has been a 50 year mismatch between computer based art and contemporary art — they were going in different directions, trying to do different things. They zoomed past each other and there was hardly time to wave hello.

Conceptual art — and neo-conceptual art if you like - were and are busy saying 'What's going on in a video picture of someone or something? Let's slow it down, open it up, question it, play with it, name the parts of it, argue about it... Computer art says 'tch tch tch tch...' the sound of a rapid shutter, or a quiet 'wheeee...' the sound of video going straight to a hard disk. If you want to do something different, it has to be done after, not during. And after is always cosmetic, and always misses the moment, and is 


\section{CAT 2010 London Conference $\sim 3^{\text {rd }}$ February Brian Reffin-Smith}

always reformist, not revolutionary. Doing art becomes synonymous with correction, with doing criticism, but with very little feedback into the art process itself because, as always, the next new thing came along, to which the critical discourse of last week rarely seemed to apply, of course. We kept thinking we'd make new and better art because of the new and better technology.

I would further suggest that this is in fact contrary to the real nature - certainly the potential, of computer art itself. In other words, computer art might have insisted might still, secretly, be insisting - that we be revolutionary. Art is not craft. It is NOT pretty pictures or interaction with aspects of a 'normal' world, even if the modes of this interaction themselves are apparently revolutionary. I mean that, for example, to be able to fly round a structure asks no critical questions at all - indeed might suppress them - of the person who imagined the structure.

It may be that ideas and techniques from older periods of computer based art are to be realised today using non-computational methods. Why not? Perhaps we should at least mentally redefine computer arts as being made by, with, or because or in spite of the computer. I know that in my teaching practice since the 1970s, and I'm sure many of you have seen this, the most interesting results have often come from a student involved in another discipline who decides to use a computer to worry at a problem, then goes back to their performance art, photography, painting or installations. That's a revolution. That, for me, is what the information revolution has been about. A revolution is turning in a circle, ending up back where you were before, but everything has changed.

I believe that ' $i$ ', the imaginary square root of minus 1 , is to the real numbers as the computer is - or should be - to art. It adds an imaginary extra dimension to the socalled 'real', or let us say to art, enabling or demanding a new, different way of doing things - a revolutionary leap of the imagination.

I belong to the Paris-based College of 'Pataphysics, where we try to, sort of, do everything like that. You may wonder what 'Pataphysics is: everyone does. The Times Literary Supplement has over several weeks asked the question "'Pataphysics — what's that?" in a debate to which I have contributed. Apart from saying that the College of 'Pataphysics was like Freemasons on acid, and is the science of exceptions, of the singularity, of the unrepeatable, I came up with the following: 'Pataphysics is to metaphysics what metaphysics is to physics:

Physics says: 'I have a computer and it makes art.' Metaphysics says 'I might have a computer and it might make art.' 'Pataphysics says 'I don't have a computer, and it makes art.' 


\section{CAT 2010 London Conference $\sim 3^{\text {rd }}$ February Brian Reffin-Smith}

I won't bring in philosophical Zombies here, those beings that are both living and dead, yes and no, 1 and 0 , true and false - but I'd like to.

It is the difficult, the problematic in computer-based arts that we should keep, rediscover, re-explore. I think we often misunderstood what art was.

The use of potentially revolutionary, multidimensional modes of computer-based or aided art production, or of quasi-artistic interaction with virtual worlds and so on, will always fail as art, if the idea of art that is addressed is mistaken: an idea of art that was probably never true and was certainly not true in the last 100 years or so.

What can we do about this? Nothing less than a complete re-examination of the history, languages, modes of discourse, theoretical frameworks and practical approaches of computer-based arts. The good news is: they're doing it! Isn't that great? Here's another good thing: I believe that if done properly, our art work and research will feed back into the modes of discourse, etc., of contemporary art as a whole, rendering it necessarily more vivid, more engaged, more investigative and less concerned with appearances. Let us not take things literally. How terrible that computer art has tended to do that! Let us re-imagine computer art.

I would follow George Spencer-Brown in seeing the universe as having - wonder of wonders! - split (whether we believe by supernatural intervention or quantum fluctuation doesn't matter here) into two parts: one of which could, for the first time ever, observe the

rest of itself. Yet in doing so, the universe necessarily became blind to part of itself. It was all OK before, just trundling along being a universe; but it couldn't see. Didn't need to, you see. Then it could see, a distinction was drawn, but it became tragically estranged from itself. This or something like it is nearly universal in myths of cosmic creation and so on.

What to do? We need, after this action, and don't forget the common etymology of 'act' and 'agony', a Truth and Reconciliation Committee. If science is the truth ('this thing happened') then art is perhaps the means of reconciliation ('we can't really mend it, but this is what it might be like if we could').

Science is perhaps socially constructed; art certainly is. Imagine Schrödinger's Cat in its box not only with a randomly triggered weapon of cat destruction but also with some paints. We don't know if it's doing art until we open the box and even then the waveform collapses not into a fact but into questions: has the cat got a gallery? Do the critics notice it? Is it in Art Monthly, Art Presse or Künstforum? If so, it's art. 


\section{CAT 2010 London Conference $\sim 3^{\text {rd }}$ February Brian Reffin-Smith}

The computer is its own box, cat, paints, experimenter and decaying isotope. It should also contain and examine its own modes of discourse and critique. Use that to make art and we necessarily bring new dimensions into play, we render art and computing 'difficult' in a positive sense. The social construction of art itself has thus opened up, allowing us to manipulate it.

We need to open everything up, to make space and time and a new dimension in the work. When the crowds of people stood around the Senster in the Evoluon in Eindhoven, as it flicked its head hither and thither, its quadrophonic microphone ears and doppler radar eyes scanning for the simplest of points of interest but giving rise to a most wonderful behaviour, it was not only the beast/sculpture to which people attended, but to the very interaction between people and Senster. A new space opened. The best interactive art always makes you look at the participants.

Let's make a revolution! Let's turn round slowly, once, and see everything, everything that was done, and then finish back here again; but everything has changed. Let's look properly at what was done, analyse it and reincorporate all the best bits, but going much further, with a new energy, the energy of the square root of minus one, of crazy 'Pataphysics, of...not Post Modernism but, perhaps, 'Post Computer Art'. 